\title{
Biomarkers for a histological chorioamnionitis diagnosis in pregnant women with or without group $B$ streptococcus infection: a case-control study
}

Jie Ren ${ }^{1}$, Zhe Qiang ${ }^{1 *}\left(\mathbb{D}\right.$, Yuan-yuan $\mathrm{Li}^{2}$ and Jun-na Zhang ${ }^{1}$

\begin{abstract}
Background: Chorioamnionitis may cause serious perinatal and neonatal adverse outcomes, and group B streptococcus (GBS) is one of the most common bacteria isolated from human chorioamnionitis. The present study analyzed the impact of GBS infection and histological chorioamnionitis (HCA) on pregnancy outcomes and the diagnostic value of various biomarkers.

Methods: Pregnant women were grouped according to GBS infection and HCA detection. Perinatal and neonatal adverse outcomes were recorded with a follow-up period of 6 weeks. The white blood cell count (WBC), neutrophil ratio, and Creactive protein (CRP) level from peripheral blood and soluble intercellular adhesion molecule-1 (sICAM-1), interleukin 8 (IL-8), and tumor necrosis factor a (TNF-a) levels from cord blood were assessed.

Results: A total of 371 pregnant women were included. Pregnant women with GBS infection or HCA had a higher risk of pathological jaundice and premature rupture of membranes and higher levels of sICAM-1, IL-8, and TNF-a in umbilical cord blood. Univariate and multivariate regression analysis revealed that sICMA-1, IL-8, TNF-a, WBC, and CRP were significantly related to an increased HCA risk. For all included pregnant women, TNF-a had the largest receiver operating characteristic (ROC) area (area: 0.841; 95\% Cl: 0.778-0.904) of the biomarkers analyzed. TNF-a still had the largest area under the ROC curve (area: 0.898; 95\% Cl: 0.814-0.982) for non-GBS-infected pregnant women, who also exhibited a higher neutrophil ratio (area: 0.815; 95\% Cl: 0.645-0.985) and WBC (area: 0.849; 95\% Cl: 0.72-0.978), but all biomarkers had lower value in the diagnosis of HCA in GBS-infected pregnant women.

Conclusion: GBS infection and HCA correlated with several perinatal and neonatal adverse outcomes. TNF-a in cord blood and WBCs in peripheral blood had diagnostic value for HCA in non-GBS-infected pregnant women but not GBS-infected pregnant women.
\end{abstract}

Keywords: Chorioamnionitis, Group B streptococcus, Biomarkers, Diagnosis, Case-control

\footnotetext{
*Correspondence: qiangzhe1983@163.com

'Second Department of Obstetrics, The Fourth Hospital of Shijiazhuang

No.206, Zhongshan East Road, Chang'an District, Shijiazhuang, Hebei,

People's Republic of China 050011

Full list of author information is available at the end of the article
}

C C The Author(s). 2021 Open Access This article is licensed under a Creative Commons Attribution 4.0 International License, which permits use, sharing, adaptation, distribution and reproduction in any medium or format, as long as you give appropriate credit to the original author(s) and the source, provide a link to the Creative Commons licence, and indicate if changes were made. The images or other third party material in this article are included in the article's Creative Commons licence, unless indicated otherwise in a credit line to the material. If material is not included in the article's Creative Commons licence and your intended use is not permitted by statutory regulation or exceeds the permitted use, you will need to obtain permission directly from the copyright holder. To view a copy of this licence, visit http://creativecommons.org/licenses/by/4.0/ The Creative Commons Public Domain Dedication waiver (http://creativecommons.org/publicdomain/zero/1.0/) applies to the data made available in this article, unless otherwise stated in a credit line to the data. 


\section{Background}

Chorioamnionitis refers to neutrophil-related inflammation in the placental and umbilical cord tissue due to microbial infection, which may cause adverse pregnancy outcomes, including premature birth, premature rupture of membranes, puerperal infection, and sepsis. The recommended term "chorioamnionitis" should be used instead of "intrauterine infection" [1]. Typical clinical symptoms include maternal body temperature $>=38^{\circ} \mathrm{C}$, purulent fluid from the vagina with a peculiar smell, a baseline fetal heart rate $>=160$ times per minute, a maternal peripheral white blood cell count (WBC) $\geq 15 \times$ $10^{9}$, uterine irritation, and a tender uterine body [2]. However, clinical symptoms often occur in late-stage pregnancy, and typical clinical chorioamnionitis have become less common with improvements in perinatal medical conditions. Occult chorioamnionitis, also known as histological chorioamnionitis (HCA), is diagnosed during the pathological examination of the placenta. These factors may cause pregnant women to not receive a timely diagnosis and treatment, which may affect the health of the mother and baby. Therefore, early diagnosis is essential.

Infection is the main cause of chorioamnionitis, and group B streptococcus (GBS) is one of the most common bacteria isolated from human chorioamnionitis [3, 4]. The mean prevalence of rectovaginal GBS colonization is $17.9 \%(95 \%$ confidence interval (CI): $16.2-22 \%$ ), of which $22.4 \%$ (95\%CI: $18.1-26.7 \%$ ) occurs in Africa, followed by $19.7 \%$ (95\% CI: 16.7-22.7\%) in the Americas and 19\% (95\%CI: 16.1-22.0\%) in Europe [5]. GBS is a $\beta$ hemolytic, Gram-positive bacterium that generally colonizes the rectum and vagina of a healthy woman, but when infection occurs during childbirth, there is an approximately $36 \%$ probability of transmission to the newborn [6]. GBS may exhibit mass propagation and transmission in utero via contaminated vaginal or amniotic fluid pumping $[7,8]$, which leads to platelet consumption, pathological coagulation (such as disseminated intravascular coagulation) and severe bacterial sepsis [9]. Neonatal invasive GBS infection is divided into two forms: early-onset disease (EOD) and late-onset disease (LOD). EOD generally occurs in the first week after birth, with pneumonia and respiratory failure accompanied by blood infections, sepsis and lowprobability meningitis. LOD occurs within 7 months with bacteremia and higher incidence of meningitis [10]. However, most newborns with GBS infection are asymptomatic, and only approximately $3 \%$ of newborns have EOD [6]. Although antibiotics are routinely used to prevent infection and are effective for EOD, well-designed randomized controlled trials (RCTs) showed that antibiotics application did not significantly reduce the incidence of HCA [11-13].

The present analyzed the impact of GBS infection on pregnancy outcomes and biomarker levels and evaluated the influence of HCA on pregnancy outcomes and the diagnostic value of various biomarkers.

\section{Methods}

This case-control research followed the strengthening of the reporting of observational studies in epidemiology reporting guidelines. This study enrolled pregnant women who had undergone prenatal checkups and delivery in local hospitals from May 2019 to March 2020. A survey was conducted in this study (Supplementary file).

\section{Inclusion and exclusion criteria}

The following inclusion criteria were used: 1 , gestational age greater than 36 weeks; 2 , no antibiotic use in the previous 4 weeks; 3 , routine GBS infection detection before delivery; 4 , singleton pregnancy; and 5, availability of cord blood, umbilical cord, and placenta after delivery. The following exclusion criteria were used: 1 , people who under 18 years old; 2, people who lacked any GBS infection test before childbirth, cord blood, umbilical cord, or placenta collection after childbirth; 3, people who had serious non-GBS infection diseases; 4, people with malignant tumor; 5 , hypertension or diabetes population; 6, genital malformation; 7, people with nephritis; and 8 , habitual abortion. The study did not limit the gravidity and parity history.

\section{GBS infection detection}

Women were divided into GBS infection and non-GBS infection groups based on the occurrence of GBS infection. Vaginal and perianal secretion samples were obtained from all women at 36-38 weeks of gestation for GBS culture. After removal of excess secretions, a sterile cotton swab was used to collect samples from the lower $1 / 3$ of the vagina and $3 \mathrm{~cm}$ inside the anus. Patients who were GBS-culture positive were classified into the GBS infection group and treated with antibiotics for preventive treatment. Penicillin G was the first choice of treatment, at an initial dose was 5 million units, followed by 2.5 million units every 4 hours until delivery. Cefazolin was used in cases of penicillin allergy. The initial dose was $2 \mathrm{~g}$, followed by $1 \mathrm{~g}$ every 8 hours until delivery. Clindamycin was used at $900 \mathrm{mg}$ every 8 hours until delivery in cases of penicillin and cefazolin allergy and bacterial sensitivity to clindamycin. If the bacteria was resistant to clindamycin, then vancomycin was used at $20 \mathrm{mg} / \mathrm{kg}$ every 8 hours until delivery.

\section{Clinical definitions}

Pathological jaundice was defined as any of the following features: clinical jaundice appearing within the first $24 \mathrm{~h}$ or after 14 days of life; increases in the levels of total bilirubin by $>8.5 \mu \mathrm{mol} / \mathrm{L}(0.5 \mathrm{mg} / \mathrm{dL})$ per hour or $(85 \mu \mathrm{mol} /$ L) $5 \mathrm{mg} / \mathrm{dL}$ per $24 \mathrm{~h}$; total bilirubin $>331.5 \mu \mathrm{mol} / \mathrm{L}(19.5$ 
$\mathrm{mg} / \mathrm{dL})$; direct bilirubin $>34 \mu \mathrm{mol} / \mathrm{L}(2.0 \mathrm{mg} / \mathrm{dL})$, which primarily referred to the National Institute for Health and Care Excellence (NICE) guideline and Queensland Clinical Guidelines. Non-reassuring fetal status was defined as progressive fetal hypoxia and/or acidemia secondary to inadequate fetal oxygenation, and it was diagnosed when any one of the following conditions was met: II-III-degree amniotic fluid meconium-staining; a fetal heart rate $>160$ beats per minute or $<120$ beats per minute for $>10 \mathrm{~min}$; an abnormal fetal heart rate (repetitive late decelerations, undulating baseline, bradycardia); or fetal movement <three times per hour or an increase or decrease of $50 \%$ compared to the previous frequency of fetal movements, with no recovery after repeated observations, which primarily referred to the National Institute of Child Health and Human Development (NICH D) guidelines $[14,15]$. Birth asphyxia was defined as failing to initiate and sustain breathing at birth. Moderate birth asphyxia was diagnostic when at least 2 of the following criteria were fulfilled: 5-min Apgar score $\leq 7$; moderate acidosis during the first hour of life: $\mathrm{pH}<7.15$ (umbilical artery, umbilical veins, capillary or arterial blood sample); and mild-to-moderate encephalopathy (Sarnat stage I-II) [16]. The present study used the World Health Organization (WHO) diagnostic criteria in combination with local guideline criteria: 1, Apgar score $\leq 7$ at $1 \mathrm{~min}$ or $5 \mathrm{~min}$, without the establishment of effective spontaneous respiration; 2, umbilical arterial blood $\mathrm{pH}<7.15$; and 3 , exclusion of other causes of low Apgar score, such as premature infants. Low birth weight was defined as a birth weight $<2500 \mathrm{~g}$. Postpartum hemorrhage was defined as an amount of bleeding $\geq 500 \mathrm{~mL}$ for vaginal delivery or $\geq 1000 \mathrm{~mL}$ for cesarean delivery within $24 \mathrm{~h}$ after delivery based on the International Federation of Gynecology and Obstetrics (FIGO) guideline [17]. Premature rupture of the membrane was defined as prelabor rupture of membranes that occurred 3 or more hours before preterm delivery. Preterm birth was defined as delivery of a newborn whose gestational age was $<37$ weeks. HCA was defined as dense polymorphonuclear leukocyte infiltration of the amnion, chorion and decidua. Puerperal infection was defined as any infection that occurred during the puerperium, such as infection of the urogenital tract, breast, and respiratory system [18]. All pregnant women and children were followed up for 6 weeks. In-hospital or telephone follow-up every 7 days after delivery to ask about neonatal jaundice and weight gain, whether the mother had fever, mastitis, lochia, and recovery of the perineal wound. Complete blood counts of mother and newborn were performed at the six-week outpatient visit follow-up. Physical examination and bilirubin determination of newborns, and recovery of the uterus were also performed at six-week follow-up.

\section{Measurement of cytokines and chemokines}

Within $24 \mathrm{~h}$ before delivery, peripheral blood was drawn for routine blood laboratory testing, and the WBCs, neutrophil ratio, and C-reactive protein (CRP) level were recorded. Cord blood was assessed for TNF- $\alpha$, sICAM-1, and IL-8 using enzyme-linked immunosorbent assay kits. The microtiter plate was precoated with antibodies from the kit, and standards and samples were added to the wells of the plate and incubated for $2 \mathrm{~h}$ at $37^{\circ} \mathrm{C}$. After washing, the biotin-avidin-horseradish peroxidase system was used for color development. Tetramethylbenzidine was used as the substrate for enzyme-linked immunosorbent assay quantitative analysis to detect the absorbance at $450 \mathrm{~nm}$. The levels of TNF- $\alpha$, IL- 8 , and sICAM1 were determined via comparison with the standard curve.

\section{Sample size assessment}

The sample size referred to a previously published study for the Chinese population, which reported an average positive rate of GBS of $13.89 \%$ during the 3-year followup. The probability of chorioamnionitis in GBS-positive patients was $16.93 \%$. The probability of chorioamnionitis in GBS-negative patients was $8.86 \%$ [19]. According to the "pwr" package of $\mathrm{R}$ language, the required total sample size was 904 at $80 \%$ power and a significance level of 0.05 . However, the incidence of HCA may be slightly lower than in this previous study because the study analyzed clinical and histological chorioamnionitis. The present study found that the positive rate of GBS was $15.9 \%$, and the positive rates of HCA in GBS-positive and negative patients were 13.56 and $3.53 \%$, respectively. The required total sample size was 283 under this condition. Therefore, we stopped the sample collection early.

\section{Statistical analysis}

Quantitative data were first assessed to determine whether the data were consistent with a normal distribution. Normally distributed data are presented as the means \pm standard deviation, and the two-sample t-test was used to analyze differences between groups. Nonnormally distributed data are presented as the median (interquartile range), and the Kruskal-Wallis rank test was used to analyze differences between groups. The qualitative data were analyzed using the chi-squared test. Pearson's correlation coefficient analysis was used to assess the correlation between variables. Univariate logistic regression was used to analyze the correlation between biomarker level and HCA. Multivariable analysis was also performed by adjusting for age, parity history and GBS infection. The receiver operating characteristic (ROC) curve was used to evaluate the accuracy of the diagnostic test and compare differences in the area under the ROC curve between the various biomarkers. All reported $P$ values were two-sided, and $P<0.05$ was 
considered significantly different. All analyses were performed using STATA software (version 14.0) and R project (version 3.6.3).

\section{Results}

The present study enrolled 371 pregnant women in local hospitals from May 2019 to March 2020. Two women were excluded for early cesarean due to oligohydramnios, and two women were excluded for unexplained fever and diagnosed with listeria infection. Fifty-nine GBS-positive patients were in the GBS group, with a mean age of $29 \pm 3.31$ years, and 312 GBS-negative patients were in the non-GBS group, with a mean age of $29.57 \pm 3.55$ years. There was no significant difference in age or parity between the two groups. Pregnant women with GBS infection had a higher risk of pathological jaundice $(p=0.013)$, premature rupture of membranes $(p=0.043)$, and HCA $(p=0.001)$. There were higher levels of sICAM-1 $(p<0.001)$, IL-8 $(p<0.001)$, and TNF$\alpha(p<0.001)$ in the umbilical cord blood of GBS-infected mothers (Table 1).

Based on HCA status, the patients were classified into HCA and non-HCA groups. Nineteen patients had HCA with 8 GBS positive, and 352 patients did not have HCA. There was no significant difference between the two groups in age or parity. HCA in patients was associated with a higher risk of pathological jaundice $(p=$ $0.005)$, fetal distress $(p=0.045)$ and low-birth-weight infants $(p<0.001)$. For parturients, there was also a higher risk of postpartum hemorrhage $(p=0.011)$, premature rupture of membranes $(p=0.001)$, and puerperal infection $(p<0.001)$. HCA patients had higher levels of sICAM-1 $(p=0.001)$, IL-8 $(p<0.001)$, and TNF- $\alpha(p<$ $0.001)$ in their cord blood and a higher $\operatorname{WBC}(p=0.008)$, neutrophil ratio $(<0.001)$, and CRP $(0.002)$ level in their peripheral blood (Table 2).

\section{Correlation analysis of multiple variables}

All included variables were subjected to correlation analysis, and the results confirmed that GBS had a high correlation with IL-8 and TNF- $\alpha$ levels. There was also a significant correlation between IL- 8 and TNF- $\alpha$. There was a negative correlation between parity and peripheral blood WBC count. TNF- $\alpha$ and IL-8 also significantly correlated with pathological jaundice, postpartum hemorrhage, premature rupture of membranes, HCA, and puerperal infection (Fig. 1).

Table 1 Characteristics of the included pregnant women grouped according to GBS infection

\begin{tabular}{|c|c|c|c|}
\hline & GBS infection & Non-GBS infection & $\overline{p \text { value }}$ \\
\hline No. & 59 & 312 & \\
\hline Age & $29(3.31)$ & $29.57(3.55)$ & 0.256 \\
\hline Median (Min-Max) & $29(21-36)$ & $29(22-40)$ & \\
\hline \multicolumn{4}{|l|}{ Parity } \\
\hline 1 & 40 & 216 & \\
\hline 2 & 18 & 85 & \\
\hline 3 & 1 & 11 & 0.698 \\
\hline Pathologic jaundice & 10 & 22 & 0.013 \\
\hline Non-reassuring fetal status & 10 & 34 & 0.187 \\
\hline Birth asphyxia & 6 & 20 & 0.300 \\
\hline Low birth weight infant & 3 & 10 & 0.472 \\
\hline Postpartum hemorrhage & 4 & 12 & 0.309 \\
\hline Premature rupture of membrane & 8 & 19 & 0.043 \\
\hline Preterm birth & 6 & 20 & 0.300 \\
\hline HCA & 8 & 11 & 0.001 \\
\hline Puerperal infection & 7 & 18 & 0.087 \\
\hline sICAM-1(ng/L) & 354.5 (323.9-368.9) & $291.3(281.3-298.4)$ & $<0.001$ \\
\hline IL-8(ng/L) & $3573(3287-3743)$ & $1075.2(1024.3-1276.4)$ & $<0.001$ \\
\hline TNF-a (ng/L) & $47.9(45.8-50.1)$ & $29.7(28.7-30.8)$ & $<0.001$ \\
\hline $\operatorname{WBC}\left(\times 10^{9}\right)$ & $8.72(7.75-11.34)$ & $8.675(7.415-11.135)$ & 0.764 \\
\hline Neutrophil ratio (\%) & $76(73-83)$ & $77(73-81)$ & 0.964 \\
\hline CRP (mg/L) & $3.5(2-10)$ & $3.2(2.5-5)$ & 0.530 \\
\hline
\end{tabular}

Abbreviations: CRP C-reation protein, GBS Group B Streptococcus, HCA Histological chorioamnionitis, IL-8 Interleukin 8, s/CAM-1 soluble Intercellular adhesion molecule-1, TNF- $a$ Tumor necrosis factor a, WBC White blood cells 
Table 2 Characteristics of the included pregnant women grouped according to HCA

\begin{tabular}{|c|c|c|c|}
\hline & HCA & Non-HCA & $p$ value \\
\hline No. & 19 & 352 & \\
\hline Age & $28.63(2.54)$ & $29.52(3.55)$ & 0.282 \\
\hline Median (Min-Max) & $29(24-36)$ & $29(21-40)$ & \\
\hline \multicolumn{4}{|l|}{ Parity } \\
\hline 1 & 17 & 239 & \\
\hline 2 & 2 & 101 & \\
\hline 3 & - & 12 & 0.135 \\
\hline GBS infection & 8 & 51 & 0.001 \\
\hline Pathologic jaundice & 5 & 27 & 0.005 \\
\hline Non-reassuring fetal status & 5 & 39 & 0.045 \\
\hline Birth asphyxia & 2 & 24 & 0.537 \\
\hline Low birth weight infant & 4 & 9 & $<0.001$ \\
\hline Postpartum hemorrhage & 3 & 13 & 0.011 \\
\hline Premature rupture of membrane & 5 & 22 & 0.001 \\
\hline Preterm birth & 2 & 24 & 0.537 \\
\hline Puerperal infection & 10 & 15 & $<0.001$ \\
\hline SICAM-1(ng/L) & $319.8(296.3-376.4)$ & $295.25(283.3-307.15)$ & 0.001 \\
\hline IL-8(ng/L) & $1534.7(1345.2-3528.1)$ & $1120.6(1025.1-1302.1)$ & $<0.001$ \\
\hline TNF-a (ng/L) & $37.1(36.4-48.1)$ & $30.1(28.9-31.4)$ & $<0.001$ \\
\hline $\operatorname{WBC}\left(\times 10^{9}\right)$ & $13.54(7.37-15.38)$ & 8.665 (7.475-10.895) & 0.008 \\
\hline Neutrophil ratio (\%) & $84(76-89)$ & $77(73-80.5)$ & $<0.001$ \\
\hline CRP (mg/L) & $12.3(3.06-32.85)$ & $3.2(2.39-5.05)$ & 0.002 \\
\hline
\end{tabular}

Abbreviations: CRP C-reation protein, GBS Group B Streptococcus, HCA Histological chorioamnionitis, IL-8 Interleukin 8, sICAM-1 soluble Intercellular adhesion molecule-1, TNF- $a$ Tumor necrosis factor $a, W B C$ White blood cells

\section{Regression analysis}

The regression analysis analyzed the relationship between biomarkers and HCA. Univariate analysis revealed that sICMA-1 (odds ratio (OR): 1.02; 95\% CI: 1.01-1.03; $p=0.001$ ), IL-8 (OR: 1.001; 95\% CI: $1,1.001 ; p=0.001$ ), and TNF- $\alpha$ (OR: 1.111; 95\% CI: $1.06-1.165 ; p<0.001$ ) were significantly related to increased HCA risk. An increased WBC (OR: 1.211; 95\% CI: 1.085-1.351; $p=$ 0.001 ), neutrophil ratio (OR: $1.179 ; 95 \% \mathrm{CI}: 1.088-1.278$; $p<0.001$ ), and CRP level (OR: 1.063; 95\% CI: $1.028-$ $1.098 ; p<0.001)$ in peripheral blood were also significantly related to the occurrence of HCA (Table 3). After adjustments were made for age, parity, and GBS infection, a significant relationship between the biomarkers and $\mathrm{HCA}$ remained.

\section{ROC curve analysis}

ROC curves were used to analyze the diagnostic accuracy of the biomarkers for HCA. First, all of the populations were analyzed. Cord blood TNF- $\alpha$ had the largest ROC area (area under ROC curve: 0.841 ; 95\% CI: $0.778-$ 0.904) of the biomarkers. The cutoff value of TNF- $\alpha$ for the population was $32.7 \mathrm{ng} / \mathrm{L}$ with $89.47 \%$ sensitivity and
78.41\% specificity (Fig. 2a). Subgroup analyses were performed according to whether GBS infection occurred. For the non-GBS infection population, TNF- $\alpha$ still had the largest area under the ROC curve (area: 0.898; 95\% CI: 0.814-0.982) when the cutoff point was $32.7 \mathrm{ng} / \mathrm{L}$ with $81.82 \%$ sensitivity and $91.69 \%$ specificity. The neutrophil ratio also had an ideal area under the curve (area: 0.815; 95\% CI: $0.645-0.985$ ) with $63.64 \%$ sensitivity and $94.35 \%$ specificity at the $88 \%$ cutoff point, and peripheral blood WBC had an ideal area under the curve (area: 0.849 ; 95\% CI: $0.72-0.978$ ) with $81.82 \%$ sensitivity and $84.72 \%$ specificity at the cutoff point of $13.19 \times 10^{9}$ and $63.64 \%$ sensitivity and $92.69 \%$ specificity at the $15.3 \times 10^{9}$ cutoff point (Fig. 2b). However, the biomarkers in the GBS-infected population had lower value in the diagnosis of HCA. Only CRP had a large area under the ROC curve (area: 0.605; 95\% CI: 0.347-0.862) (Fig. 2c) (Table 4).

\section{Discussion}

Chorioamnionitis is primarily caused by infections related to a variety of serious perinatal and neonatal adverse outcomes. However, typical clinical symptoms are 


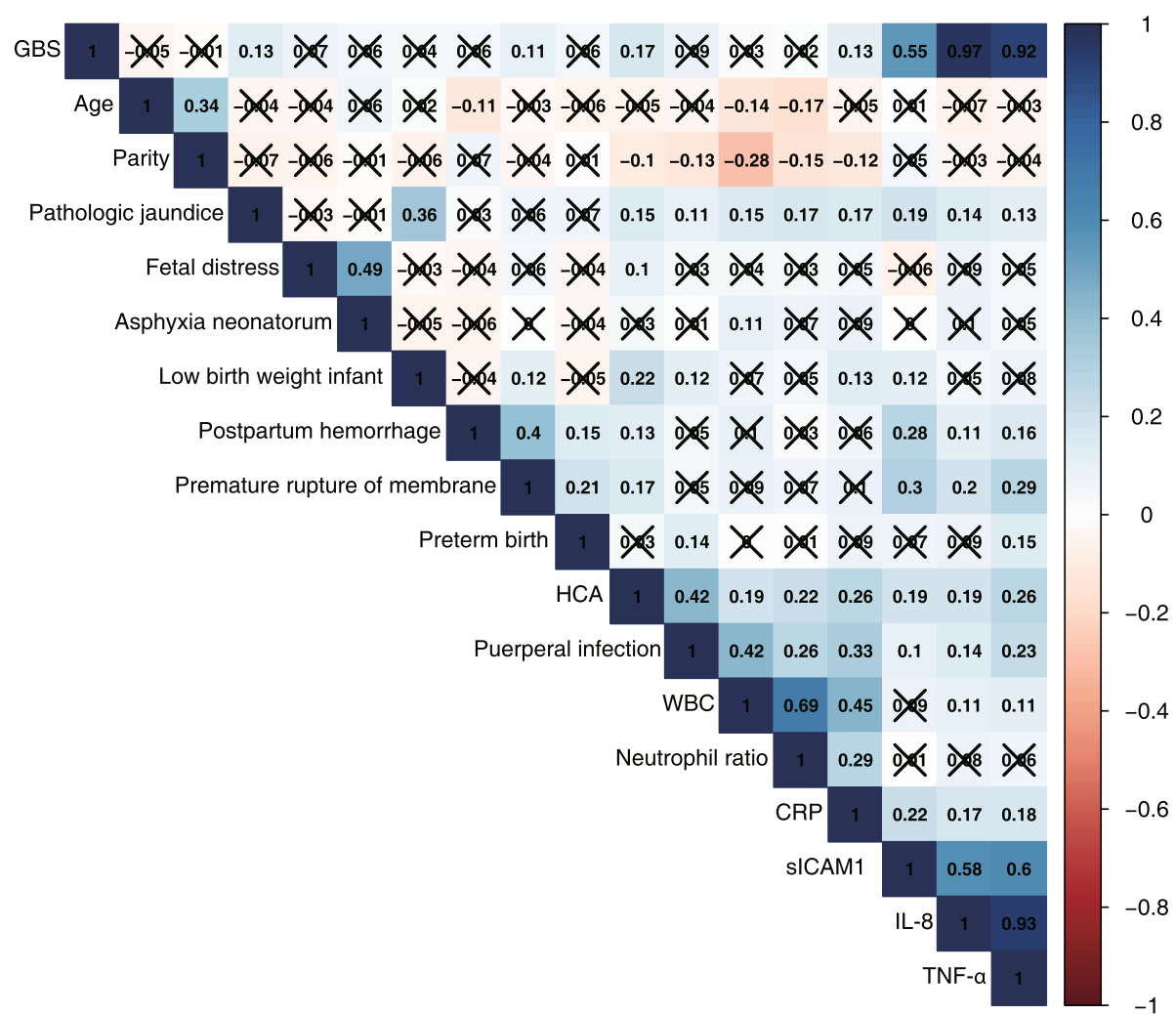

Fig. 1 Correlation plot of the multiple variables included in this work. The results without significant differences are marked

rare, and many insidious cases of HCAs do not receive timely diagnosis and treatment, which adversely affects maternal and child health. However, ideal indicators for the diagnosis of $\mathrm{HCA}$ in prenatal examinations are lacking.

GBS is a common opportunistic pathogen that is routinely screened before delivery. Invasive GBS infection is also an important cause of neonatal abnormalities and mortality [20], and preterm birth, neonatal encephalopathy and stillbirth significantly correlate with GBS infection [21-23]. With the spread of antibiotic prophylaxis, the rate of invasive GBS infection decreased from 1.1 to $0.3 \%$ [24]. A recent systematic review showed an invasive GBS infection incidence of 0.49 per 1000 live births (95\% $\mathrm{CI}, 0.43-0.56)$, in which EOD incidence was 0.41 (95\% CI, $0.36-0.47$ ) with $78 \%$ sepsis and $16 \%$ meningitis, and LOD was 0.26 (95\% CI, $0.21-0.30$ ) with $53 \%$ sepsis and $43 \%$ meningitis [25]. The mean case fatality ratio was 8.4 to $9.6 \%[25,26]$. A meta-analysis of the incidence of HCA in a population with normal delivery outcomes is lacking, but approximately $12.7 \%$ had HCA in one study based on Bangladeshi population [27], and the incidences of acute

Table 3 Relationship between biomarker indicators and HCA by regression analysis

\begin{tabular}{|c|c|c|c|c|c|c|c|c|}
\hline \multirow{3}{*}{$\begin{array}{l}\text { Indicators } \\
\text { sICAM1 }\end{array}$} & \multicolumn{4}{|c|}{ Univariate analysis } & \multicolumn{4}{|c|}{ Multivariate analysis $^{\mathrm{a}}$} \\
\hline & \multirow{2}{*}{$\begin{array}{l}\text { Odd ratio } \\
1.020\end{array}$} & \multicolumn{2}{|c|}{ 95\% Confidence Interval } & \multirow{2}{*}{$\begin{array}{l}\boldsymbol{p} \text { value } \\
0.001\end{array}$} & \multirow{2}{*}{$\begin{array}{l}\text { Odd ratio } \\
1.018\end{array}$} & \multicolumn{2}{|c|}{ 95\% Confidence Interval } & \multirow{2}{*}{$\frac{p \text { valu }}{0.015}$} \\
\hline & & 1.010 & 1.03 & & & 1.004 & 1.033 & \\
\hline IL-8 & 1.001 & 1.000 & 1.001 & 0.001 & 1.002 & 1.000 & 1.004 & 0.038 \\
\hline TNF-a & 1.111 & 1.060 & 1.165 & $<0.001$ & 1.329 & 1.160 & 1.522 & $<0.001$ \\
\hline Neutrophil ratio & 1.179 & 1.088 & 1.278 & $<0.001$ & 1.172 & 1.078 & 1.275 & $<0.001$ \\
\hline WBC & 1.211 & 1.085 & 1.351 & 0.001 & 1.174 & 1.044 & 1.32 & 0.007 \\
\hline CRP & 1.063 & 1.028 & 1.098 & $<0.001$ & 1.052 & 1.019 & 1.085 & 0.002 \\
\hline
\end{tabular}

Abbreviations: CRP C-reation protein, GBS Group B Streptococcus, HCA Histological chorioamnionitis, IL-8 Interleukin 8, sICAM-1 soluble Intercellular adhesion molecule-1, TNF- $a$ Tumor necrosis factor $a, W B C$ White blood cells

${ }^{a}$ Adjust for adjusting for age, parity, and GBS infection 

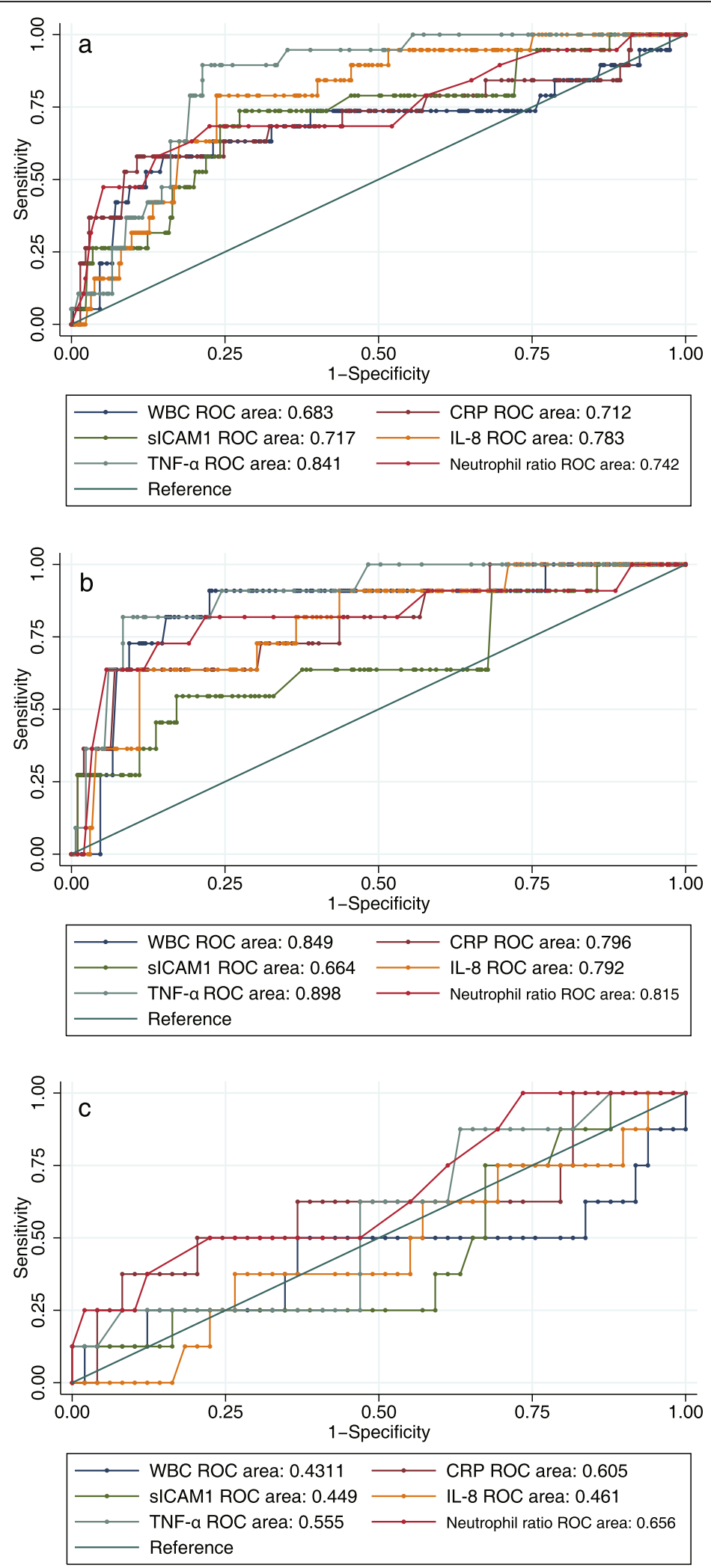

Fig. 2 The ROC curves for HCA diagnosis with biomarkers. a Total pregnancy; b Pregnant without GBS infection; c Pregnant with GBS infection 
Table 4 The area under ROC curve for HCA diagnosis with biomarkers

\begin{tabular}{|c|c|c|c|c|c|}
\hline \multirow{2}{*}{$\begin{array}{l}\text { Population } \\
\text { Total pregnant }\end{array}$} & \multirow{2}{*}{$\begin{array}{l}\text { Biomarkers } \\
\text { TNF- } a\end{array}$} & \multirow{2}{*}{$\begin{array}{l}\text { No. } \\
366\end{array}$} & \multirow{2}{*}{$\begin{array}{l}\text { ROC area } \\
0.841\end{array}$} & \multicolumn{2}{|c|}{ 95\% Confidence Interval } \\
\hline & & & & 0.778 & 0.904 \\
\hline & IL-8 & 366 & 0.783 & 0.693 & 0.873 \\
\hline & sICAM-1 & 366 & 0.717 & 0.590 & 0.844 \\
\hline & Neutrophil ratio & 366 & 0.742 & 0.605 & 0.879 \\
\hline & WBC & 366 & 0.683 & 0.524 & 0.842 \\
\hline & CRP & 366 & 0.712 & 0.559 & 0.866 \\
\hline \multirow[t]{6}{*}{ Non-GBS infection } & TNF-a & 309 & 0.898 & 0.814 & 0.982 \\
\hline & IL-8 & 309 & 0.792 & 0.659 & 0.925 \\
\hline & sICAM-1 & 309 & 0.664 & 0.469 & 0.858 \\
\hline & Neutrophil ratio & 309 & 0.815 & 0.646 & 0.985 \\
\hline & WBC & 309 & 0.849 & 0.721 & 0.977 \\
\hline & CRP & 309 & 0.796 & 0.646 & 0.946 \\
\hline \multirow[t]{6}{*}{ GBS infection } & TNF-a & 57 & 0.555 & 0.337 & 0.773 \\
\hline & IL-8 & 57 & 0.461 & 0.237 & 0.684 \\
\hline & sICAM-1 & 57 & 0.449 & 0.219 & 0.679 \\
\hline & Neutrophil ratio & 57 & 0.656 & 0.435 & 0.876 \\
\hline & WBC & 57 & 0.431 & 0.150 & 0.712 \\
\hline & CRP & 57 & 0.605 & 0.347 & 0.862 \\
\hline
\end{tabular}

Abbreviations: CRP C-reation protein, GBS Group B Streptococcus, HCA Histological chorioamnionitis, IL-8 Interleukin 8, s/CAM-1 soluble Intercellular adhesion molecule-1, TNF- $a$ Tumor necrosis factor $a, W B C$ White blood cells

and chronic HCA were approximately 12.9 and $12.7 \%$, respectively, in another study based on an American population [28]. HCA also significantly correlated with fetal adverse outcomes, including sepsis, bronchopulmonary dysplasia, intraventricular hemorrhage, necrotizing enterocolitis, and cerebral palsy [29-32]. The present study found that GBS infection significantly correlated with pathological jaundice, premature rupture of membranes, and HCA. Patients with HCA had a higher risk of pathological jaundice, fetal distress, and low-birth-weight infants. For parturients, there was also a higher risk of postpartum hemorrhage, premature rupture of membranes, and puerperal infection. For the biomarkers, TNF$\alpha$ was accurate for the HCA diagnosis in non-GBSinfected pregnant women but not in the GBS-infected population. The neutrophil ratio and WBCs were also potential diagnostic biomarkers for HCA in the non-GBS infection population, which meets one of the diagnostic criteria for clinical chorioamnionitis.

The present study first confirmed that GBS infection increased TNF- $\alpha$ levels in cord blood. Mechanistically, GBS regulates the activation of the transcription factors NF- $\mathrm{KB}$ and AP-1 via the $\mathrm{p} 38$-MAPK pathway in human cord blood mononuclear cells to increase TNF- $\alpha$ expression and secretion [33]. TNF- $\alpha$ further activates the p38MAPK pathway of neutrophils to promote the aggregation of neutrophils, which increases the risk of chorioamnionitis [34]. Although a clinical study suggested that TNF- $\alpha$ level was not significantly different in cord blood between pregnancies with and without clinical chorioamnionitis [35], our result was different, and this difference may be due to discrepant clinical and HCA diagnostic criteria. The present study suggests that TNF$\alpha$ may help the diagnosis HCA, but whether an invasive measurement of TNF- $\alpha$ levels in cord blood is necessary to predict the risk of HCA requires further discussion.

The present study also found that an elevated TNF- $\alpha$ level, neutrophil ratio, and WBCs had more diagnostic accuracy for HCA in non-GBS-infected pregnant women. This result indicated that an elevated TNF- $\alpha$ level, neutrophil ratio, and WBCs caused by factors other than GBS infection may be important factors in causing HCA. Escherichia coli, GBS, and enterococcus species are the main types of infectious bacteria that affect birth outcomes [36]. Bacteria may vary between people in different regions. These bacteria may also increase the level of TNF- $\alpha$ in cord blood [37]. Another pathogen, human ureaplasma, also causes chorioamnionitis [38]. Intrauterine infection caused by ureaplasma was also related to TNF-a regulation in animal models [39]. GBS colonization lost its correlation with chorioamnionitis with routine GBS screening and prophylaxis in developed countries and even became negatively correlated [40]. Due to the preventive application of antibiotics in GBS-positive pregnant women, the probability of other opportunistic pathogen infections was 
reduced, which reduced the risk of HCA. Pregnant women with GBS infection also underwent routine antibiotic application in our study, which may explain why no diagnostic value was found for any examined biomarker for HCA. Therefore, whether to expand the antibiotic application standards to non-GBS-infected pregnant women with a high $\mathrm{WBC}$, neutrophil ratio, or TNF- $\alpha$ level to reduce the risk of HCA needs further consideration.

In addition to the diagnostic value of TNF signaling, basic research showed that the inhibition of TNF signaling silenced the expression of $80 \%$ of infection-related genes that encode proinflammatory factors in response to lipopolysaccharides (LPS) and reduced the accumulation and activation of neutrophils at the feto-maternal interface [41]. Therefore, whether TNF signaling inhibition could prevent HCA in high-risk pregnant women to avoid serious adverse perinatal and neonatal outcomes requires further study.

In general, the diagnosis of clinical chorioamnionitis patients relies too heavily on the judgment of fever, which results in a $15 \%$ higher prevalence of clinical chorioamnionitis for HCA [42]. However, some patients with HCA lack the typical clinical manifestations [43]. This difference in diagnostic criteria for clinical chorioamnionitis and HCA results in heterogeneity between studies [44]. HCA is only confirmed via delayed pathological detection, but it was not achieved in every puerpera, which may lead to a missed diagnosis or loss of treatment opportunity. Therefore, biomarkers are needed to help diagnose HCA. A meta-analysis found that maternal CRP and WBC count showed low sensitivity and specificity for HCA diagnosis [45]. The present study found that the level of TNF- $\alpha$ detected from umbilical cord blood during delivery showed higher sensitivity and specificity that provided clues for HCA diagnosis. GBS colonization screening was generally performed, and antibiotics prophylaxis was used in positive populations. TNF- $\alpha$ had high diagnostic sensitivity and specificity in GBS-negative patients for HCA diagnosis. Therefore, TNF- $\alpha$ in cord blood may be measured at the same time as delivery. Increased maternal and infant monitoring and active antibiotic intervention should be performed as early as possible in patients with high levels of TNF- $\alpha(>32.7 \mathrm{ng} / \mathrm{L})$ to prevent HCA-related complications.

The present study had some limitations. First, the types of biomarkers were insufficient, and biomarkers, such as IL-6, were not studied. Second, we still need to follow local diagnostic criteria for clinical outcome description for clinical outcomes diagnostic criteria. The diagnostic criteria recommended in international guidelines are not fully followed. This difference will cause some error between the number of cases in the present work and the number of cases under international guidelines. Third, this work analyzed only pregnant women in the local population, and whether TNF- $\alpha$ has diagnostic accuracy for pregnant women in other regions and countries must be confirmed.

\section{Conclusion}

In conclusion, GBS infection and HCA correlated with several perinatal and neonatal adverse outcomes, respectively. TNF- $\alpha$ in cord blood and the WBCs in peripheral blood had diagnostic value for $\mathrm{HCA}$ in nonGBS-infected pregnant women but not GBS-infected pregnant women.

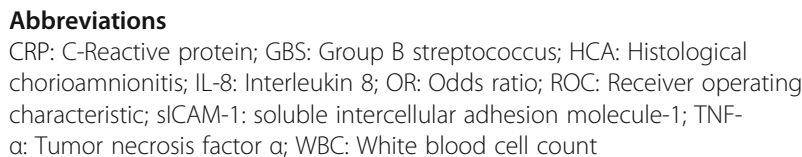

\section{Supplementary Information}

The online version contains supplementary material available at https://doi. org/10.1186/s12884-021-03731-7.

Additional file 1.

\section{Acknowledgments}

Not applicable.

\section{Authors' contributions}

JR and ZQ contributed to the conception, design, conduct, and drafting of the original study. $Y L$ and JZ performed the statistical analyses and figure editing. All authors contributed to the interpretation and revision of the final manuscript. All authors have read and approved the final manuscript.

\section{Funding}

These trials and data analysis were financially supported by Shijiazhuang Science and Technology Research and Development Plan (No.191460803). The funding agency had no role in the design, conduct, analysis, and interpretation of the findings or in the decision to publish.

Availability of data and materials

The datasets used and/or analyzed during the current study are available from the corresponding author on reasonable request.

\section{Declarations}

Ethics approval and consent to participate

The research protocol was approved by the institutional ethics committee of the fourth hospital of Shijiazhuang at Jun. 20, 2019 (No.20190051). All participants agreed to participate in this study and signed an informed consent form before sample collection.

Consent for publication

Not applicable.

\section{Competing interests}

The authors declare that they have no competing interests.

\section{Author details}

'Second Department of Obstetrics, The Fourth Hospital of Shijiazhuang, No.206, Zhongshan East Road, Chang'an District, Shijiazhuang, Hebei, People's Republic of China 050011. 2Perinatal center, The Fourth Hospital of Shijiazhuang, Shijiazhuang, Hebei, People's Republic of China 050000. 
Received: 22 September 2020 Accepted: 17 March 2021 Published online: 25 March 2021

\section{References}

1. Peng CC, Chang JH, Lin HY, Cheng PJ, Su BH. Intrauterine inflammation, infection, or both (triple I): a new concept for chorioamnionitis. Pediatr Neonatol. 2018;59(3):231-7. https://doi.org/10.1016/j.pedneo.2017.09.001

2. Oh KJ, Kim SM, Hong JS, Maymon E, Erez O, Panaitescu B, et al. Twenty-four percent of patients with clinical chorioamnionitis in preterm gestations have no evidence of either culture-proven intraamniotic infection or intraamniotic inflammation. Am J Obstet Gynecol. 2017;216:604 e1-e11.

3. Botelho RM, Tenorio LPG, Silva ALM, Tanabe ELL, Pires KSN, Goncalves CM, et al. Biomechanical and functional properties of trophoblast cells exposed to group B Streptococcus in vitro and the beneficial effects of uvaol treatment. Biochim Biophys Acta Gen Subj. 1863;2019:1417-28.

4. Allard MJ, Giraud A, Segura M, Sebire G. Sex-specific maternofetal innate immune responses triggered by group B streptococci. Sci Rep. 2019;9(1): 8587. https://doi.org/10.1038/s41598-019-45029-X.

5. Kwatra G, Cunnington MC, Merrall E, Adrian PV, Ip M, Klugman KP, et al. Prevalence of maternal colonisation with group B streptococcus: a systematic review and meta-analysis. Lancet Infect Dis. 2016;16(9):1076-84 https://doi.org/10.1016/S1473-3099(16)30055-X.

6. Seedat F, Geppert J, Stinton C, Patterson J, Freeman K, Johnson SA, et al. Universal antenatal screening for group B streptococcus may cause more harm than good. BMJ. 2019;364:1463.

7. Shabayek S, Spellerberg B. Acid stress response mechanisms of group B streptococci. Front Cell Infect Microbiol. 2017;7:395. https://doi.org/10.3389/ fcimb.2017.00395.

8. Andrade EB, Magalhaes A, Puga A, Costa M, Bravo J, Portugal CC, et al. A mouse model reproducing the pathophysiology of neonatal group $B$ streptococcal infection. Nat Commun. 2018;9(1):3138. https://doi.org/10.103 8/s41467-018-05492-y.

9. Uchiyama S, Sun J, Fukahori K, Ando N, Wu M, Schwarz F, et al. Dual actions of group B Streptococcus capsular sialic acid provide resistance to plateletmediated antimicrobial killing. Proc Natl Acad Sci U S A. 2019;116:7465-70.

10. Doran KS, Fulde M, Gratz N, Kim BJ, Nau R, Prasadarao N, et al. Hostpathogen interactions in bacterial meningitis. Acta Neuropathol. 2016; 131(2):185-209. https://doi.org/10.1007/s00401-015-1531-z.

11. Taha TE, Brown ER, Hoffman IF, Fawzi W, Read JS, Sinkala M, et al. A phase III clinical trial of antibiotics to reduce chorioamnionitis-related perinatal HIV-1 transmission. AIDS. 2006;20(9):1313-21. https://doi.org/10.1097/01.aids. 0000232240.05545.08.

12. Goldenberg RL, Mwatha A, Read JS, Adeniyi-Jones S, Sinkala M, Msmanga G, et al. The HPTN 024 study: the efficacy of antibiotics to prevent chorioamnionitis and preterm birth. Am J Obstet Gynecol. 2006;194(3):65061. https://doi.org/10.1016/j.ajog.2006.01.004.

13. Goldenberg RL, Mudenda V, Read JS, Brown ER, Sinkala M, Kamiza S, et al. HPTN 024 study: histologic chorioamnionitis, antibiotics and adverse infant outcomes in a predominantly HIV-1-infected African population. Am J Obstet Gynecol. 2006;195(4):1065-74. https://doi.org/10.1016/j.ajog.2006.05.046.

14. Gravett C, Eckert LO, Gravett MG, Dudley DJ, Stringer EM, Mujobu TB, et al. Non-reassuring fetal status: case definition \& guidelines for data collection, analysis, and presentation of immunization safety data. Vaccine. 2016;34(49): 6084-92. https://doi.org/10.1016/j.vaccine.2016.03.043.

15. Garabedian C, Butruille L, Drumez E, Servan Schreiber E, Bartolo S, Bleu G, et al. Inter-observer reliability of 4 fetal heart rate classifications. J Gynecol Obstet Hum Reprod. 2017;46(2):131-5. https://doi.org/10.1016/j.jogoh.201 6.11 .002$.

16. Endrich O, Rimle C, Zwahlen M, Triep K, Raio L, Nelle M. Asphyxia in the newborn: evaluating the accuracy of ICD coding, clinical diagnosis and reimbursement: observational study at a Swiss tertiary care center on routinely collected health data from 2012-2015. PLoS One. 2017;12(1): e0170691. https://doi.org/10.1371/journal.pone.0170691.

17. Lalonde A, International Federation of G, Obstetrics. Prevention and treatment of postpartum hemorrhage in low-resource settings. Int J Gynaecol Obstet. 2012;117:108-18.

18. Karsnitz DB. Puerperal infections of the genital tract: a clinical review. J Midwifery Womens Health. 2013;58(6):632-42. https://doi.org/10.1111/ jmwh.12119.
19. Zhu Y, Huang J, Lin XZ, Chen C. Group B Streptococcus colonization in late pregnancy and invasive infection in neonates in China: a population-based 3-year study. Neonatology. 2019;115:301-9.

20. Huang J, Li S, Li L, Wang X, Yao Z, Ye X. Alarming regional differences in prevalence and antimicrobial susceptibility of group B streptococci in pregnant women: a systematic review and meta-analysis. J Glob Antimicrob Resist. 2016;7:169-77. https://doi.org/10.1016/j.jgar.2016.08.010.

21. Bianchi-Jassir F, Seale AC, Kohli-Lynch M, Lawn JE, Baker CJ, Bartlett L, et al. Preterm birth associated with group B Streptococcus maternal colonization worldwide: systematic review and meta-analyses. Clin Infect Dis. 2017; 65(suppl_2):S133-S42. https://doi.org/10.1093/cid/cix661.

22. Tann CJ, Martinello KA, Sadoo S, Lawn JE, Seale AC, Vega-Poblete M, et al. Neonatal encephalopathy with group B streptococcal disease worldwide: systematic review, Investigator Group datasets, and meta-analysis. Clin Infect Dis. 2017:65(suppl_2):S173-S89. https://doi.org/10.1093/cid/cix662.

23. Seale AC, Blencowe H, Bianchi-Jassir F, Embleton N, Bassat Q, Ordi J, et al. Stillbirth with group B Streptococcus disease worldwide: systematic review and meta-analyses. Clin Infect Dis. 2017;65(suppl_2):S125-S32. https://doi. org/10.1093/cid/cix585.

24. Russell NJ, Seale AC, O'Sullivan C, Le Doare K, Heath PT, Lawn JE, et al. Risk of early-onset neonatal group B streptococcal disease with maternal colonization worldwide: systematic review and meta-analyses. Clin Infect Dis. 2017;65(suppl_2):S152-S9. https://doi.org/10.1093/cid/cix655.

25. Madrid L, Seale AC, Kohli-Lynch M, Edmond KM, Lawn JE, Heath PT, et al. Infant group B streptococcal disease incidence and serotypes worldwide: systematic review and meta-analyses. Clin Infect Dis. 2017;65(suppl_2):S160S72. https://doi.org/10.1093/cid/cix656.

26. Edmond KM, Kortsalioudaki C, Scott S, Schrag SJ, Zaidi AK, Cousens S, et al. Group B streptococcal disease in infants aged younger than 3 months: systematic review and meta-analysis. Lancet. 2012;379(9815):547-56. https:// doi.org/10.1016/S0140-6736(11)61651-6

27. Chan GJ, Silverman M, Zaman M, Murillo-Chaves A, Mahmud A, Baqui AH, et al. Prevalence and risk factors of chorioamnionitis in Dhaka, Bangladesh. J Perinatol. 2016;36(12):1039-44. https://doi.org/10.1038/jp.2016.150.

28. Romero R, Kim YM, Pacora P, Kim CJ, Benshalom-Tirosh N, Jaiman S, et al. The frequency and type of placental histologic lesions in term pregnancies with normal outcome. J Perinat Med. 2018;46(6):613-30. https://doi.org/10.1 515/jpm-2018-0055.

29. Villamor-Martinez E, Lubach GA, Rahim OM, Degraeuwe P, Zimmermann LJ, Kramer BW, et al. Association of Histological and Clinical Chorioamnionitis with Neonatal Sepsis among Preterm Infants: a systematic review, metaanalysis, and meta-regression. Front Immunol. 2020;11:972. https://doi.org/1 0.3389/fimmu.2020.00972.

30. Villamor-Martinez E, Alvarez-Fuente M, Ghazi AMT, Degraeuwe $P$, Zimmermann LJ, Kramer BW, et al. Association of Chorioamnionitis with Bronchopulmonary Dysplasia among Preterm Infants: a systematic review, meta-analysis, and Metaregression. JAMA Netw Open. 2019;2(11):e1914611. https://doi.org/10.1001/jamanetworkopen.2019.14611.

31. Villamor-Martinez E, Fumagalli M, Mohammed Rahim O, Passera S, Cavallaro $G$, Degraeuwe $P$, et al. Chorioamnionitis is a risk factor for Intraventricular hemorrhage in preterm infants: a systematic review and meta-analysis. Front Physiol. 2018;9:1253. https://doi.org/10.3389/fphys.2018.01253.

32. Shi Z, Ma L, Luo K, Bajaj M, Chawla S, Natarajan G, et al. Chorioamnionitis in the development of cerebral palsy: a meta-analysis and systematic review. Pediatrics. 2017;139(6):e20163781. https://doi.org/10.1542/peds.2016-3781.

33. Vallejo JG, Knuefermann P, Mann DL, Sivasubramanian N. Group B Streptococcus induces TNF-alpha gene expression and activation of the transcription factors NF-kappa B and activator protein-1 in human cord blood monocytes. J Immunol. 2000;165(1):419-25. https://doi.org/10.4049/ jimmunol.165.1.419.

34. Tong M, Potter JA, Mor G, Abrahams VM. Lipopolysaccharide-stimulated human fetal membranes induce neutrophil activation and release of vital neutrophil extracellular traps. J Immunol. 2019;203(2):500-10. https://doi. org/10.4049/jimmunol.1900262.

35. Romero R, Chaemsaithong P, Docheva N, Korzeniewski SJ, Tarca AL, Bhatti $\mathrm{G}$, et al. Clinical chorioamnionitis at term V: umbilical cord plasma cytokine profile in the context of a systemic maternal inflammatory response. J Perinat Med. 2016:44:53-76.

36. Page JM, Bardsley T, Thorsten V, Allshouse AA, Varner MW, Debbink MP, et al. Stillbirth associated with infection in a diverse U.S. cohort. Obstet Gynecol. 2019;134(6):1 187-96. https://doi.org/10.1097/AOG.0000000000003515. 
37. Mohamed MA, Cunningham-Rundles S, Dean CR, Hammad TA, Nesin M Levels of pro-inflammatory cytokines produced from cord blood in-vitro are pathogen dependent and increased in comparison to adult controls. Cytokine. 2007;39(3):171-7. https://doi.org/10.1016/j.cyto.2007.07.004

38. Sweeney EL, Dando SJ, Kallapur SG, Knox CL. The human Ureaplasma species as causative agents of Chorioamnionitis. Clin Microbiol Rev. 2017; 30(1):349-79. https://doi.org/10.1128/CMR.00091-16.

39. Silva JR, Ferreira LF, Oliveira PV, Nunes IV, Pereira IS, Timenetsky J, et al. Intra-uterine experimental infection by Ureaplasma diversum induces TNFalpha mediated womb inflammation in mice. An Acad Bras Cienc. 2016; 88(Suppl 1):643-52. https://doi.org/10.1590/0001-3765201620150244.

40. Venkatesh KK, Vladutiu CJ, Glover AV, Strauss RA, Stringer JSA, Stamilio DM, et al. Is group B Streptococcus colonization associated with maternal Peripartum infection in an era of routine prophylaxis? Am J Perinatol. 2020 https://doi.org/10.1055/s-0040-1709666.

41. Presicce P, Cappelletti M, Senthamaraikannan P, Ma F, Morselli M, Jackson CM, et al. TNF-signaling modulates neutrophil-mediated immunity at the Feto-maternal Interface during LPS-induced intrauterine inflammation. Front Immunol. 2020;11:558. https://doi.org/10.3389/fimmu.2020.00558.

42. Wu YW, Colford JM Jr. Chorioamnionitis as a risk factor for cerebral palsy: a meta-analysis. JAMA. 2000;284(11):1417-24. https://doi.org/10.1001/jama.2 84.11.1417.

43. Palmsten K, Nelson KK, Laurent LC, Park S, Chambers CD, Parast MM. Subclinical and clinical chorioamnionitis, fetal vasculitis, and risk for preterm birth: a cohort study. Placenta. 2018;67:54-60. https://doi.org/10.1016/j.pla centa.2018.06.001.

44. Venkatesh KK, Leviton A, Hecht JL, Joseph RM, Douglass LM, Frazier JA, et al. Histologic chorioamnionitis and risk of neurodevelopmental impairment at age 10 years among extremely preterm infants born before 28 weeks of gestation. Am J Obstet Gynecol. 2020;223:745 e1-e10.

45. Catano Sabogal CP, Fonseca J, Garcia-Perdomo HA. Validation of diagnostic tests for histologic chorioamnionitis: systematic review and meta-analysis. Eur J Obstet Gynecol Reprod Biol. 2018;228:13-26. https://doi.org/10.1016/j. ejogrb.2018.05.043.

\section{Publisher's Note}

Springer Nature remains neutral with regard to jurisdictional claims in published maps and institutional affiliations.

Ready to submit your research? Choose BMC and benefit from:

- fast, convenient online submission

- thorough peer review by experienced researchers in your field

- rapid publication on acceptance

- support for research data, including large and complex data types

- gold Open Access which fosters wider collaboration and increased citations

- maximum visibility for your research: over $100 \mathrm{M}$ website views per year

At $\mathrm{BMC}$, research is always in progress.

Learn more biomedcentral.com/submissions 